\title{
Policy Analysis of China's New Energy Vehicle Industry Policy
}

\author{
Jiahang $\mathrm{He}^{1, \mathrm{a},{ }^{*}, \dagger}$, Wanting $\mathrm{Yin}^{2, \mathrm{~b}, *, \dagger}$ \\ ${ }^{1}$ Department of Agricultural \& Applied Economics, University of Wisconsin-Madison. Madison, WI, U.S.A. \\ ${ }^{2}$ Department of Economics, Dalhousie University. Halifax, Nova Scotia, Canada. \\ ${ }^{*}$ Corresponding author.Email: ${ }^{a}$ jhe248@wisc.edu, ${ }^{b}$ wn8211126@dal.ca \\ 'These authors contributed equally.
}

\begin{abstract}
In order to achieve carbon neutralization, energy conservation and carbon emission reduction have come into focus. In the process of striving to achieve carbon emissions, new energy vehicles have gradually become the key development industry for many countries around the world to achieve energy conservation and emission reduction. This paper analyzes the development process of new energy vehicles and related enterprises in China through literature analysis, case study, and summary induction in the past few years. It selects BYD as the representative enterprise for research. It covers the technical innovation of new energy vehicles, subsidy policies, future development prospects, and suggests some suggestions. The value of this article is the analysis and optimization of China's new energy vehicle industrial policy.
\end{abstract}

Keywords: China, New energy vehicles, Subsidy policy, strategies

\section{INTRODUCTION}

In 2020's United Nations General Assembly, President $\mathrm{Xi}$ announced that China will reach the peak of its carbon emission before 2030 and finally achieve 'carbon neutralization' by 2060 [1]. To achieve carbon neutrality, replacing traditional petrol vehicles with $\mathrm{New}$ Energy vehicles is an effective solution since $\mathrm{CO} 2$ emitted by vehicles powered by fossil fuel is one of the biggest carbon sources. As the New Energy vehicles are crucial to reduce the emission of $\mathrm{CO} 2$ and achieve carbon neutralization, many countries, especially developed countries and big developing countries with high carbon emission rates, are doing their best to popularize the New Energy vehicles nationwide with policies. For instance, California, one of the states of the U.S., has come up with Zero Emission Vehicle (ZEV) program to transform the structure of vehicle usage from traditional cars to zero-emission vehicles in the state [2]; Norwegian government has also been working on New Energy vehicles adoption by setting the electrification policy.

While many countries have different policies and subsidies to encourage the popularization of $\mathrm{New}$ Energy vehicles, China, as the biggest carbon-emission country in the world with more than 10.06 billion metric tons of CO2 produced in 2018 solely [3], has also been popularizing the usage of New Energy vehicles by subsidizing the New Energy vehicles consumers since 2009. However, the existing subsidy policy causes a big expense for the government and causes pressure on the country's finance [4]. Since 2016 the Chinese government has been reducing the number of subsidies for various reasons. Even though the government extended the subsidies of electric vehicles from 2020 to 2022 due to the COVID-19 pandemic, the subsidy will finally be canceled at the end of 2022. China has one of the biggest electric vehicle markets globally with total sales exceeded 1.36 million in 2020 and shares $44 \%$ of all the electric vehicles in the world with more than 4.5 million in number. The subsidy has a very strong effect and helps the popularization of electric vehicles a lot, so the cancellation of the subsidy may have a very strong impact. So far, we do not know what the Chinese market will become when the subsidy is gone.

As a key to sustainable economic development, new energy vehicles have become the focus of attention of all countries in the world. Countries around the world have set up many policies for the development of new energy vehicles. China has two policies, including consumer subsidies and other subsidies. We now know that China's new energy vehicle subsidy policy is on a 
downward slope and will be eliminated by the end of 2022. However, we do not know why China has removed the subsidy policies, how China's new energy vehicle industry will be affected, and what measures will be taken after removing these policies. At the same time, we only know little about the policy changes of new energy vehicles in the world. Therefore, what we need to do is to summarize the existing policies of China and other countries, as well as the relevant policies of new energy vehicles in other countries in the coming years, to predict the overall trend of the future new energy vehicle industry, and how China can promote new energy vehicles and how to become more competitive in the world market.

In this research, we use literature analysis, case study, and summary induction. Through the policy research on New Energy vehicles, the development of New Energy vehicles has great significance, which can reduce the oil demand and achieve the purpose of energy conservation and environmental protection.

\section{METHODOLOGY}

\subsection{Literature Analysis}

First, we will analyze various kinds of documents and journals to get a basic understanding of the policy of the Chinese government on the electric vehicle, including subsidy, tax, market regulations, and company management. To get first-hand information from government authorities, we will collect information from government websites, especially the State Council website. The main information we are going to collect are (1) Data related to the number of subsidies, if available, of different areas and cities; (2) Past and current policies of subsidies; (3) The main reason for the government to reduce subsidies and finally cancel them by the end of 2022; (4) How does the COVID-19 pandemic impact the electric vehicle market, as well as big companies in the field, in 2020 .

\subsection{Case Study and Comparison}

The second method we are going to use is comparative analysis. As many countries in the world have been coming up with distinguished policies to encourage the usage of electric vehicles, we want to compare different policies from two angles to understand the effectiveness of China's subsidy policies on electric vehicles and the policies' revolution.

The first comparison method is horizontal comparison. By comparing the evolution of subsidy policies, the number of subsidies in different phases of popularization, as well as the change of policy along with difficult periods including the trade war and COVID-19 pandemic throughout years, we can get to know how the subsidy came out and the reason why the subsidy will finally disappear.

The second comparison method is vertical comparison, which compares China's subsidy policies with other countries' policies related to the promotion of environmental-friendly vehicles. For this part, we will list several countries that came up with governmentissued policies for the popularization and compare them with the Chinese government's policies. Even though different countries have distinguished conditions, comparing different policies can better understand other countries' experiences and help the Chinese government plan the next step of electric vehicle development after the subsidy is cancelled.

Moreover, we are also going to pick a representative Chinese electric vehicle company to discuss the overall situation of this company from these two comparative perspectives. They are depicting the history of this company's development under the long-term subsidy policy throughout years (horizontal comparison) and comparing the company's status quo with companies based in other countries from the same field (vertical comparison). Although policies are authoritative, they are not intuitive enough to let us view the effect of policies on companies and consumers. Understanding the performance and tactics of a single company with statistics can be more straightforward. For this part, we will employ BYD Co. Ltd (BYD), one of the biggest electric-vehicle producers in China, to conduct the research. We will dig deeper into BYD's development history since it was founded in 2003, focusing on its electric vehicle development under the government's subsidy policies from 2009. We will also compare its strategy and development condition with some other companies, including Xpeng Co. Ltd and NIO Co. Ltd from China and Tesla Co. Ltd and Renault-NissanMitsubishi Alliance Co. Ltd (RNM Alliance) from other countries.

\subsection{Summary Induction}

The third method that we are going to use is the method of summary induction, which is to take multiple examples and generalize common features to get to a conclusion. In the early stage of development, the new energy vehicle industry has immature technology, an imperfect industrial chain, and weak market demand, so it needs to rely on the subsidies and welfare policies of the national government to support enterprises. This paper summarizes the opportunities and threats that China's new energy vehicles will encounter when the policy is canceled through the study of policy subsidies. Taking BYD as an example, when the subsidy intensity is reduced, it summarizes its response measures. It puts forward suggestions for the development of subsidy policies for new energy vehicles in the future. As consumers' demand for the intelligence of new energy 
vehicles gradually increases, how will BYD improve its intelligence to increase its market share?

\section{RESULT}

\subsection{Under the background of the elimination of subsidies, the opportunities, and threats that China's new energy vehicles may face}

\subsubsection{The Background of China's Subsidy Policy}

The new energy vehicle subsidy policy refers to the policy issued by the government to promote the development of new energy vehicles, mainly for vehicles driven by new power energy. New energy vehicle subsidy policies mainly include consumer subsidy policies and other subsidy policies. Among them, consumer subsidy policies generally mean that the government directly provides cash or financial support to the consumer. By reducing the sales price of new energy vehicle, to achieve the purpose of expanding sales. Other types of subsidy policies include technology research and development subsidies, car restriction policies, and charging pile policies, which drive the development of the whole industry.

At the beginning of 2020, China's new energy vehicle market declined due to multiple factors. To support the development of new energy vehicles industry with high quality, promote consumption, 'Notice on Financial Subsidy Policy for Promotion and Application of New Energy vehicles' released in April 2020 [5], extending subsidies for new energy vehicles to the end of 2022, and pointed out that the new energy vehicle purchase subsidy will be a state of regression in 2021 and 2022, stabilize market expectations. In the early stage of development, the new energy vehicle industry has immature technology, an imperfect industrial chain, and weak market demand. Thus, it needs to rely on the subsidies and welfare policies of the national government to support enterprises. However, as the technology matures, the industry chain improves, and the market demand increases, the government begins to reduce the subsidy quota.

\subsubsection{Opportunities and Threats that China's New Energy Vehicles May Face}

The price of new energy vehicles has dropped sharply, which has greatly stimulated market demand and attracted consumers. Consumer subsidies are of great significance to the development of the industry. They promote new energy vehicles to grab market share and lay a foundation for future development. However, with the end of the market cultivation period, a market with relatively sufficient competition between old and new enterprises, new energy vehicles, and fuel vehicles has been formed. The gradual withdrawal of subsidies is inevitable.

The opportunity to cancel the subsidy policy for new energy vehicles has temporarily increased the sales volume, and the powerful enterprises will develop better. For the new energy vehicle industry, the sales of new energy vehicles will be significantly increased before the subsidy policy is canceled. Many consumers are enjoying new energy vehicle subsidies before the subsidy retreat. In addition, it is a good thing for consumers. The retrograde policy has new requirements for the range and battery structure of new energy vehicles. Vehicles with a range of fewer than 300 kilometers will not be subsidized, eliminating inferior enterprises, and leaving excellent enterprises to provide excellent products for consumers. It is also a good thing for fuel vehicles. When the subsidy policy is canceled, new energy vehicles and traditional fuel vehicles will return to the same starting line to achieve the same stage of the competition.

The threat after the cancellation of the subsidy policy for new energy vehicles is also obvious. The market will eliminate the enterprises relying on the policy subsidy. For consumers, compared with new energy vehicles, fuel cars are more convenient for longdistance travel. Because the charging pile is not universal, new energy vehicles are not convenient for the users of some districts. For enterprises, after the cancellation of the subsidy policy for new energy vehicles, the production cost rises, which means that enterprises, suppliers, and consumers need to bear the increased cost. For enterprises, accelerating product innovation, enhancing product competitiveness, reducing costs by technology, reducing costs by scale is the most reliable way.

\subsection{Current Situation of Industrial Policy of New Energy Vehicles Abroad}

To encourage the development of new energy vehicles, China began to implement a new energy vehicle subsidy policy in 2009. While China is vigorously encouraging the development of new energy vehicles, other countries in the world have also introduced various subsidy policies to encourage the development of new energy vehicles.

\subsubsection{Analysis of Industrial Policy in the United} States

To encourage consumers to buy new energy vehicles, the U.S. government offers preferential policies from several aspects [6]: 


\subsubsection{Income Tax Deduction}

In May 2007, the US Internal Revenue Service adjusted the personal income tax deduction for consumers of new energy vehicles. For models that meet the subsidy standard, the limit is set at the accumulative sales volume of 60,000 vehicles. After reaching 30,000 vehicles, consumers will have a $50 \%$ tax reduction. More than 45,000 vehicles will have a $25 \%$ tax cut; More than 60,000 vehicles will not have any tax breaks.

\subsubsection{2. 'Emergency Economic Stabilization Act'}

In 2008, 'Emergency Economic Stabilization Act' stipulated that; starting from January 1, 2009, the first 250,000 consumers who purchased new energy vehicles would have tax credits ranging from $\$ 2,500$ to $\$ 7,500$. In addition, state governments have added other policies, such as Florida waived the extra cost of vehicle insurance. Some state governments have provided millions of dollars in additional retrograde tax credits. The highest amount is in Georgia, at $\$ 20,000$, focus on commercial vehicles and electric vehicles.

\subsubsection{What Other States Do}

Some states take the form of consumption tax relief, consumption vouchers, and other subsidies. Most notably, California is the only state so far to use this policy, preferring to set standards and let the market regulate itself.

\subsubsection{Analysis of Industrial Policy in Japan}

In the late 20th century, Japan proposed a new energy technology research and development program. After the 21 st century, the development strategy of new energy vehicles was clarified.

\subsubsection{1. 'New Generation Vehicle Strategy 2010'}

In April 2010, Japan released the "New Generation Vehicle Strategy 2010"[7], which has become the main guiding principle of Japan's new energy vehicle development strategy. The strategic target values are proposed from the aspects of the proportion of different types of vehicles, battery performance, and cost, charging stations. For example, the "New Generation Vehicle Strategy 2010" published by the Japanese government clearly defines the development goals of new-generation vehicles: by 2020 , the sales proportion will reach 50 percent; by 2030, it will be 70 percent.

\subsubsection{The Implementation of 'Green Taxation'}

Japan implemented the "green taxation". Applicable objects including electric vehicles, hybrid cars, clean diesel, the three kinds of the car was defined as "next- generation cars". In addition to the subsidy, the purchase of this type of car will receive a $100 \%$ weight tax deduction and tax deduction. Some offer a $50 \%$ reduction in the auto tax. Japan mentioned in the "New Generation Vehicle Strategy 2010", it plans to build 2 million regular charging stations and 5,000 quickcharging stations across the country by 2020 .

\subsubsection{Analysis of Industrial Policy in China}

Table 1. The Development Stages of New Energy Vehicles in China

\begin{tabular}{ll}
\hline Years & Policies \\
\hline $2009-$ & China's subsidy policy experienced a starting and \\
2015 & rising stage \\
$2016-$ & China's consumption subsidy policy was in a \\
2020 & declining stage \\
2020 & $\begin{array}{l}\text { Due to the COVID-19, China decided to extend } \\
\text { the subsidy to 2022 }\end{array}$ \\
\hline
\end{tabular}

From 2009 to 2015, to adapt to the initial stage of developing the new energy vehicle industry, the government issued several subsidy policies to support the rapid expansion of the new energy vehicle market. In 2009, China's new energy vehicle subsidy policy was in its infancy. In this section, China's State Council, the Ministry of Finance, and other departments issued various notices and plans. Its content stipulates the subsidy standard of various types of energy vehicles. Set up planning objectives, financial subsidies, and measures to promote new energy vehicles. In June 2009, the Ministry of Industry and Information Technology released the "Energy Vehicle Production Enterprises and Product Access Management Rules" to further improve and binding the "New Energy Vehicle Production Access Management Rules", with the introduction and improvement of the provisions, it marks the rise of new energy vehicles for the national industrial technology strategy [8].

From 2010 to 2015, the national policy further strengthened the promotion of new energy vehicles. At first, five cities in China -- Shanghai, Changchun, Shenzhen, Hangzhou, and Hefei -- launched pilot subsidies to purchase new energy vehicles. The central government will provide one-time subsidies to plug-in hybrid and pure electric passenger cars purchased, registered, and implemented in pilot cities. The subsidy standard is determined according to the energy of the power battery pack. For the new energy vehicles that meet the supporting conditions, the subsidy will be given at the rate of $3,000 \mathrm{RMB} / \mathrm{kWh}$. The subsidy is up to 50,000 RMB per plug-in hybrid car and 60,000 RMB per pure electric car [9]. The subsidy funds will be delivered to the vehicles production enterprises, which will sell the new energy vehicles to private users or leasing enterprises at their prices after deducting the subsidies. The governments of the pilot cities are the subject of implementation and responsibility of the pilot project of purchasing new energy vehicles. And they 
should arrange certain funds and introduce corresponding supporting policies and measures. Given support on charging station's infrastructure construction, purchase and use of new energy vehicles, battery scrap and recovery system. When the market of new energy vehicles is fully saturated, and the sales volume rises to the national standard, the state begins to implement the subsidy regression policy. During the COVID-19 pandemic in 2020, the sales of new energy vehicles declined, which made the government postpone the time of cancelling the policy subsidies for new energy vehicles.

\subsection{Analysis on the Development Status of China's New Energy Vehicle Enterprises- Take BYD Co.Ltd as an Example}

As one of the oldest and biggest vehicles producing enterprises in China, BYD Co. Ltd (shorten as BYD). Started with producing traditional fuel cars and batteries, researched, and developed electric cars, and experienced rapid development when the government introduced the subsidy policies in 2009 [10]. As the leader of Chinese electric vehicles, BYD's electric car made various achievements in the past years. They have high-quality to ensure the safety of products and various models to fulfill the need of different groups of customers. These made them one of the biggest electric vehicle companies in the world.

However, behind the high-speed development, BYD also faces hardship in recent years. As a company relies heavily on government subsidies, BYD's after-subsidy future is not bright. First, with the emergence of some new electric vehicle firms such as XPeng Co. Ltd and NIO Co. Ltd, the market share of BYD has constantly decreased since 2017. Moreover, as a firm that heavily depends on government subsidies, BYD keeps positive profit by getting subsidies for firms. When the subsidy is totally cancelled, they must develop other strategies to make profits as one of their important profit resources is gone.

\section{DISCUSSION}

Throughout the information retrieving from government documents and journals, comparing China's government policies on new energy vehicles from horizontal and vertical perspectives, and discussing the Chinese representative firm BYD, we have a clear view about the challenges the Chinese new energy vehicle faces market is viewing. While the Chinese market of new energy vehicles might experience a small boom before the end of 2022, the sales volume has a very high possibility to drop dramatically after the subsidy is totally gone. Due to various reasons, including the Trade War between China and the U.S. and the COVID19 pandemic, the electric vehicle market did not increase significantly in 2020 . Therefore, we predict that the Chinese electric vehicle market will experience a period of shrinkage soon after the subsidy is totally gone at the end of 2022, and the government will need to find a new method to further popularize electric vehicles as the popularization of electric vehicles still has a long way to go. The State Council had already published a White Book about the development plan for the new energy vehicle industry from 2021 to 2035 in November 2020. The White Book talks about several points that would further help the Chinese market grow.

\subsection{Improving Companies' After-sales Services}

The first policy is improving the after-sales service. Since the electric vehicle market is still on its way to being totally mature compared to traditional fuel cars, the after-sales service chain is not fully constructed, creating a gap between customers' expectations and the car's actual performance. For instance, the recharge mileage of the electric vehicle is a very common aspect that would make a gap. Some companies exaggerate the recharge mileage and do not include the battery replacement into the insurance, which would create a gap between the customer and company and unfavorable to the overall popularization of electric vehicles. Therefore, improving the after-sales service system and meeting customers' needs is crucial for long-term development.

\subsection{Increasing the Number of New Energy Vehicle Charging Piles}

Increasing the number of new energy vehicle charging piles is also an important part of the marketing improvement. Currently, the charging-pile stations are not widespread everywhere like a gas station in China, especially in small cities. This indicates charging the vehicle could be a problem for long-distance travelling and travelling to small cities. Building standardized charging stations in more cities and working on the electric vehicle's infrastructure system can not only improve customers' experience but also maintain the healthy development of the industry.

Even though these plans are not directly related to the subsidy policies we talked about, these points show that the government is very concerned about the longterm development of the electric vehicles market in China. After the subsidy policies are gone, these plans would be the backbone to ensure the development of the electric vehicle market.

\subsection{Reducing Taxation}

Besides the current plan from the State Council, there is another possible method for the government to develop the market size of new energy vehicles, especially electric vehicles. From the experience of the 
U.S. and Japan, the reduction of taxation is widely implemented and received positive feedbacks. Even though China's tax system is totally different from the countries mentioned above. Since the sale tax of vehicles is included in the price in China, sometimes it is not easy to separate the tax from the price itself, making the taxation reduction harder to be carried out. However, our thought is that the government can reduce taxation from aspects other than the vehicle. The consumers may get a taxation reduction share on some other taxable parts of their life, including but not limited to income, estate. Offering quota to the consumer as another format of "subsidy" could effectively decrease the government's financial pressure, thus achieving long-term development of the market.

\section{CONCLUSION}

In this paper, we analyzed the whole history and progress of the Chinese government's subsidy policy on new energy vehicles. We compared them with other countries' policies on popularizing electric vehicles. The most important outcome of the paper is that the government needs to develop new policies as they are reducing the subsidy and finally cancelling it by the end of 2022. The main point for popularizing the new energy vehicles, especially electric vehicles, after the subsidy is cancelled is improving customers' experience. Since the electric vehicles are powered by the battery, indicating insufficient endurance for travelling and an inefficient charging process, the government should develop policies to alleviate the impact of these two deficiencies on the customer experience besides solving the problem from the technical perspective.

There are several limitations worth noting. First, most of the data and policy analysis are retrieved from the Internet directly. Some analyses are based on datasets from journals but not government documents. Due to the lack of available first-hand data, some parts of the analysis of the current situation and forecasting can be inaccurate and biased. Further research will be needed to verify the reliability of the suggestions of plans after the subsidy period. Moreover, since most companies' future planning is internal documentation and cannot be directly shared on the Internet with the public, we have limited knowledge about how companies will deal with the subsidy problem for the post-subsidy period. Thus, further research is necessary.

\section{REFERENCES}

[1] Frangoul, A. (September 23, 2020). President Xi tells UN that China will be 'carbon neutral' within four decades. Sustainable Energy. https://www.cnbc.com/2020/09/23/china-claims-itwill-be-carbon-neutral-by-the-year-2060.htmlJ.

[2] J.P. Muehlegger, E. \& Rapson, D. (December 2018). Subsidizing low-and-middle income adoption of electric vehicles: quasi-experimental evidence from California. National Bureau of Economics Research.

[3] Union of Concerned Scientists. (August12, 2020). Each country's share of $\mathrm{CO} 2$ emissions. https://www.ucsusa.org/resources/each-countrysshare-co2-emissions

[4] M. Fan, J., Wang, J., Zhang, X. 2020. An innovative subsidy model for promoting the sharing of Electric Vehicles in China: A pricing decisions analysis. Energy(201)15.https://doi.org/10.1016/j.energy.20 20.117557

[5] Chinese Ministry of Finance. (2020, December 31). Notice on Financial Subsidy Policy for Promotion and Application of New Energy vehicles. http://www.gov.cn/zhengce/202012/31/content_5575908.htm.

[6] Chuandong (2018, March 16). An inventory of subsidy policies for new energy vehicles around the

world.https://www.chuandong.com/news/news211 349.html.

[7] Wang, X. (2010, September 16). Overall strategy of "New Generation Vehicle Strategy 2010." http://www.istis.sh.cn/list/list.aspx?id=6608.

[8] Yang, T., Chen, X., \& Li, X. (2021, January 25). Evaluation and analysis of new-energy vehicle industry policies in the context of technical innovation in China. https://www.sciencedirect.com/science/article/abs/ pii/S0959652620351702?via\%3Dihub.

[9] Lo, K. (2013, September 23). A critical review of China's rapidly developing renewable energy and energy efficiency policies. https://www.sciencedirect.com/science/article/abs/ pii/S1364032113006655?via\%3Dihub.

[10] BYD U.S.A. Co Ltd. Official Website. https://en.byd.com/. 